\title{
Frozen Retail Poultry Meat Contact Surfaces as Sources of Salmonella and Escherichia Coli Contamination in Ibadan, Oyo State, Nigeria
}

\author{
Dr OLAYINKA Ishola*, ADEYANJU Gladys Taiwo \\ Department of Veterinary Public Health and Preventive Medicine, University of Ibadan, Nigeria \\ *Corresponding author: olayinkaishola@yahoo.com
}

Received March 03, 2014; Revised April 02, 2014; Accepted October 07, 2014

\begin{abstract}
Food contact surfaces serve as sources of food contamination. These contact surfaces if not properly washed are additional sources of foodborne pathogens predisposing to foodborne illnesses. Of importance is contact surfaces of raw unprocessed meat. Contact surfaces from which frozen poultry meat are been sold in Bodija and Academy areas of Ibadan, Oyo State, Nigeria, comprising wooden tables, weighing scales and cutting knives, were assayed to access levels of contamination with preference to Escherichia coli and Salmonella spp. Microbiological Standards and Guidelines by USDA (National Agricultural library) and NCCLS guidelines (from Global Salm-Surv, 2003) were used during the research work. Statistical software SPSS for Windows was used for statistical analysis (SPSS Inc., 1992). The study was approved by the Ethical Research Review Board (ERRB), University of Ibadan, Ibadan, Nigeria. Forty-two swab samples were randomly taken from contact surface materials, fourteen each of wooden tables, knives and weighing scales used in retail sales of poultry meat. From the forty-two (42) swab samples collected, log mean $\mathrm{cfu} / \mathrm{cm}^{2} \pm \mathrm{SD}$ of Aerobic Plate Count was at $7.78 \pm 0.35$ while for Enterobacteriaceae counts, it was at $7.65 \pm 0.33$. ISO 6579: 2002 was used for Salmonella isolation and ISO-16654:2001 for Escherichia coli isolation. Fifteen (15) Salmonella isolates were obtained comprising ten (10) from knives at 23.8\%, five (5) from weighing scales at $11.9 \%$ and non (0) from wooden tables (0\%) while sixteen (16) Escherichiacoli isolates, eight from (8) knives,five from (5) scales and three from (3) wooden tables, at $7.1 \%, 19 \%$ and $11.9 \%$ were respectively obtained. The reflection of the work is that these meat contact surface materials will serve as further sources of cross contamination if not properly cleaned before use.
\end{abstract}

Keywords: food contamination, poultry meat, contact surfaces, cross contamination, Enterobacteriaceae, Escherichia coli, Salmonella spp.

Cite This Article: Dr OLAYINKA Ishola, and ADEYANJU Gladys Taiwo, "Frozen Retail Poultry Meat Contact Surfaces as Sources of Salmonella and Escherichia Coli Contamination in Ibadan, Oyo State, Nigeria." Journal NamAmerican Journal of Epidemiology and Infectious Disease, vol. 2, no. 4 (2014): 81-85. doi: 10.12691/ajidm-2-4-2.

\section{Introduction}

Meat contains sufficient nutrient needed to support the growth of microorganisms and is therefore considered as the most perishable of all important food (Magnus, 1981). Epidemiological reports suggest that poultry meat is still the primary cause of human food poisoning (Mulder, 1999) as poultry meat and its derivatives are among the food products that cause the most concern to public health authorities, owing to the associated risks of bacterial food poisoning. A noticeable increase in the instances of foodborne illness attributed to the mishandling of poultry meat and other poultry products has been noticed in the last decade.Common sanitary problems that occur during the handling of poultry meat are basically the condition and cleanliness of contact surfaces and the safety of water used in retail processing, usually from a municipal source of wells, used in the cleaning of meat contact surfaces.
(New York State Department of Agriculture and Markets, 2011).

Microorganisms which cause bacteria food poisoning are obtained either directly through contaminated food or through cross-contamination with already contaminated surfaces (during processing or sale) and are usaully from the enterobacteriacea family.Verotoxigenic Escherichia coli (VTEC) and Salmonella spp.amongst others are common contaminants along the processing line.

Salmonella spp. are pathogenic bacteria responsible for one of the most frequent foodborne diseases. Over 2500 known types, or serotypes, of Salmonella have been isolated so far. However, Salmonella entericaserovars Enteritidis and Typhimurium are the Salmonella types most frequently associated food poisoning leading to illness in human when these organisms are ingested through raw or improperly processed food (Panisello et al., 2000). Clinically discernible syndromes of Salmonellosis occurring in man are acute onset of fever, abdominal pain, diarrhoea, nausea and sometimes vomiting. 
Several strains of Escherichia coliexist and so is their ability to cause disease in human. However, symptoms of food poisoning with $E$. coli in human ranges from diarrhoea in infants that can last for over 2 weeks and results in death if dehydration is severe, while in adults, it is characterized by severe diarrhoea, nausea, vomiting, abdominal cramps, headache, fever, chills, bloody diarrhoea (hemorrhagic colitis) (NIAID2011). The Shiga toxin producing strains or categories cause diarrheal illnesses or disease in human: enteropathogenicE. coli (causes severe diarrhoea in infants), enteroinvasiveE. coli (similar to shigellosis), enterotoxigenicE. coli (responsible for "traveler' sdiarrhoea"), Shiga toxin-producing E. coli (cause severe enteric and systemic disease in humans) and enterohemorrhagicE. coli (E. coli O157:H7), which is the most important to public health as a source of emerging disease (Encyclopedia of Public Health, 2011).

\subsection{Meat Contact Surfaces and Bacteria Pathogens}

The presence of bacterial pathogens in meat-processing equipment and associated surfaces may contribute to the contamination of meat. It is generally accepted that microbial loads on surfaces and equipment vary in different food plants depending on the microbial quality of the food (Evans et al.,2004).

It is already known that most bacteria form biofilm on hydrated surfaces (Costertonet al., 1999). Most of these bacteria have the ability of producing a matrix of biofilms which protect them from external harm and enables them to adhere strongly to contact surfaces making it necessary to go an extra mile during cleaning.

Typical food contact surfaces in Nigerian retail markets may include handlers hands and outer garments, wooden tables, cutting knives, weighing scales, carton papers, cleaning sponges/brushes, aprons and water-holding utensils such as metal buckets or plastic containers. These food handling equipment should therefore be maintained and stored in a way that will minimise the chance of food becoming contaminated as their contamination can contribute to cross-contamination of non-contaminated poultry meat. Microorganisms, once in the interior of the wood, may persist in the inner structure. Improperly washed weighing scales and cutting knives may also have biofilms with bacteria within their matrix. Unlesssuch equipment are thoroughly sanitized, they may continue to contaminate foodstuff as noted (Costerton et. al 1999; Hassan et. al., 2010). Hence, uncontaminated poultry meat will become contaminated by the time it comes in contact with such surface. On the other hand, contaminated meat is able also to disseminate food-borne pathogens to clean contact-surfaces (Gorman et. al., 2002). Contamination is therefore vice-versa. NSW Food Authourity (2011) states that"product that has been distributed to other businesses and/or the consumer may need to be recalled if it is contaminated with harmful microorganisms, contaminated with harmful chemicals, contaminated with physical matter such as glass or wood, or has been tampered with".

However, because of the difficulty in attaining this, consumers are advised to properly cook these poultry products such that theinternalcooking temperature reaches $165^{\circ} \mathrm{F}\left(74^{\circ} \mathrm{C}\right)$ as recommended by New York State Department of Agriculture and Markets (2011).

\section{Materials and Methods}

The study was carried out in Academy and Bodija areas of Ibadan. 10mls of buffered peptone water was added to sterile swabs which was used to obtain samples from contact surfaces. Collection was dependent on the cooperation of the shop owners. Fourteen samples each of some raw poultry meatcontact-surfaces comprising wooden tables, cutting knives and weighing scales, were swabbed using surface swab technique as described in the Compendium of Methods for the Microbiological Examination of Foods (American Public Health Association, 1992) where $10-15 \mathrm{~cm}^{2}$ surface area of each contact surface was obtained. Samples were transported to the laboratory in a cold chain where each tube containing the swab was vortexed 10 seconds to properly mix the sample. Aerobic plate count (APC), Enterobacteriaceae counts (ENT), Salmonella isolation (using ISO-6579: 2002 standard procedures)and Escherichia coli isolation(using ISO-16654:2001standard procedures) were all carried out (ISO standard catalogue,2011).All bacteria counts are transformed to $\log 10$ values.Statistical software SPSS for Windows was used for statistical analysis (SPSS Inc., 1992).

1. Aerobic plate count (APC) and Enterobacteriaceae counts (ENT).

Swab samples in 9mls buffered peptone water (LabM®, UK) gave a dilution ratio of 1:10.A six-fold serial dilution was prepared for each sample and $0.1 \mathrm{ml}$ of dilutions $10^{-6}$ and $10^{-5}$ for every sample was respectively plated on plate count agar (PCA) (Biomark ${ }^{\circledR}$, India) for aerobic plate count determination and on MacConkey agar (MCA) (LabM®, UK) for Enterobacteriaceae counts and incubated overnight (18-24 hours) at $37^{\circ} \mathrm{C}$. A digital colony counting chamber was used to count distinct colonies on PCA and MCA (pink colonies) and recorded in colony forming units per $\mathrm{cm}^{2}\left(\mathrm{cfu} / \mathrm{cm}^{2}\right)$ of swab sampled using the formula:

$$
\begin{aligned}
c f u / \mathrm{cm}^{2} & =\text { level of dilution plated } \\
& \times \text { number of colonies counted/volume plated } .
\end{aligned}
$$

They were expressed in mean colony forming units per gram (mean cfu/ $\mathrm{cm}^{2}$ ) and in log 10 base values.

\section{Salmonella isolation.}

a. Non-selective pre-enrichment: labelled swab samples were properly vortexed to $\mathrm{mix}$ with the preenrichment medium (buffered peptone water, LabM $\left.{ }^{\circ}, \mathrm{UK}\right)$ and incubated overnight (18-20 hours) at $37^{\circ} \mathrm{C}$.

b. Selective enrichment: $0.1 \mathrm{ml}$ of the pre-enrichment was taken using a sterile pipette and transferred into rubber cap-screw test-tubes containing $10 \mathrm{mls}$ of already prepared Rappaport-Vassiliadis soya peptone broth (Oxoid $\AA$, England). Test-tubes were labeled accordingly and incubated at $41.5^{\circ} \mathrm{C} \pm 0.5^{\circ} \mathrm{C}$ overnight (18-24 hours).

c. Selective agar plating: Fresh Brilliant green agar (BGA) (LabM ${ }^{\circledR}$, UK) plates were prepared after which $10 \mu \mathrm{l}$ wire loop-full volume from the RVS broth wasspread out on the plates, labelled, inverted and incubated overnight (18-24 hours) at $37^{\circ} \mathrm{C}$.

d. Sub-cultivation: Nutrient agar (LabM®, UK) plates were prepared and suspect colonies which caused the 
color of the medium to change from yellow to red/pink were sub-cultivated and incubated overnight (18-24hours) at $37^{\circ} \mathrm{C}$.

3. Escherichia coliisolation.

a. Enrichment: Serial six-fold dilution in buffered peptone water (LabM $\AA$, UK) was prepared $\left(10^{-1}\right.$ to $10^{-6}$ ) for test swab samples. Fresh MCA (LabM®, UK) plates were prepared and $0.1 \mathrm{ml}$ of dilutions $10^{-6}$ and $10^{-5}$ for every sample was respectively plated on the MCA and spread out using glass spreader. These were then labelled, inverted and incubated at $37^{\circ} \mathrm{C}$ overnight (18-24 hours).

b. Sub-cultivation: Fresh MCA (LabM®, UK) plates were prepared and presumptive pinkish colonies (coliform) obtained from incubated plates were subcultivated unto them, followed by labelling and incubation of plates overnight (18-24 hours) at $37^{\circ} \mathrm{C}$.

c. Plating on Nutrient agar: Isolates were transferred into nutrient slants, labelled and incubated overnight (18-24hours) at $37^{\circ} \mathrm{C}$, ready for biochemical analysis.

Biochemical tests carried out are catalase test, sugar fermentation using TSI (LabM, Uk), Mannitol test and Gram stainingfor Salmonella spp. and catalase test, sugar fermentation using TSI (LabM, Uk),Kovac's test and Gram stainingfor Escherichia coli isolates.

\section{Results and discussions}

1. Aerobic plate count and enterobacteriaceae counts.

Table 1 shows the APC and ENT counts of the materials sampled represented in Figure 1. Counts obtained from research, where APC counts for cutting knives, weighing scales and wooden tables at 7.73 7.69,7.91cfu/g respectively, showed slight difference from swab APC counts of 10.2, 9.2 and $8.5 \mathrm{cfu} / \mathrm{g}$ observed in cutting knives, weighing scales and wooden boards respectively by Hassanet. al (2010). However, food-borne pathogens found in retail shops could be sources for horizontal contamination of meat through processing equipment unto meat. It is already known that bacteria form biofilm on hydrated surfaces (as they use up the water present on these surfaces) making them more adherent to the contact surfaces such that they develop the ability to resist any form of clearance or removal from these surfaces either by use of water or sanitizers (Hassanet al., 2010). It then implies that meat can be further contaminated by such equipment on which biofilms may have formed.

Table 1. Aerobic plate counts and Enterobacteriaceae counts for knives, tables and scales

\begin{tabular}{|c|c|c|c|}
\hline Materials & $\mathrm{n}$ & $\begin{array}{c}\text { Aerobic plate count } \\
\text { cfu/g }\end{array}$ & $\begin{array}{c}\text { Enterobactriaceae counts } \\
\text { cfu/g }\end{array}$ \\
\hline Table & 14 & $7.91 \pm 0.19$ & Mean \pm SD \\
\hline Scales & 14 & $7.69 \pm 0.44$ & $7.76 \pm 0.19$ \\
\hline Knives & 14 & $7.73 \pm 0.35$ & $7.55 \pm 0.38$ \\
\hline Total & 42 & $7.78 \pm 0.35$ & $7.64 \pm 0.36$ \\
\hline
\end{tabular}

key: n- numbers of samples collected, SD- standard deviation, cfu/gcolony forming unit per gram.

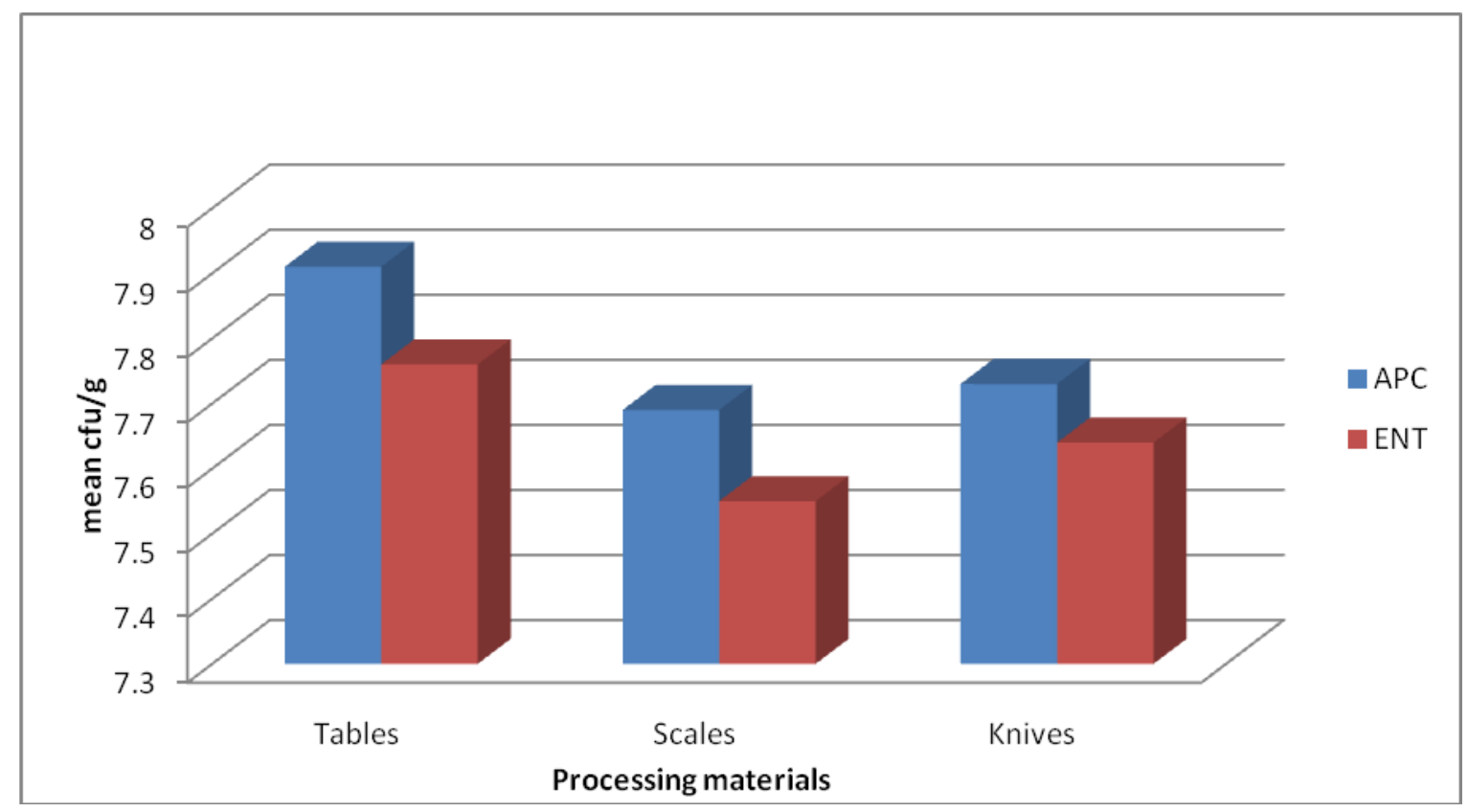

Figure 1. APC and ENT counts for materials used in sales of poultry meat in retail markets

Key: cfu/g - colony forming unit per gram, APC- aerobic plate counts, ENT - enterobacteriaceae counts.

2. Salmonella and Escherichiacoli isolation

Fifteen (15) Salmonella isolates were obtained from swab samples comprising ten (10) from knives and five (5) from weighing scales at $66.67 \%$ and $33.33 \%$ respectively while for Escherichiacoli, sixteen (16) isolates from swabs comprising three (3) wooden tables, eight (8) knives and five (5) scales at $18.75 \%, 50 \%$ and $31.25 \%$ respectively are shown in Figure 2.
Escherichia coli and Salmonella spp. amongst others as noted are common contaminants of equipment used in processing of meat which are able to produce biofilm (Costertonet al., 1999). Their presence therefore on contact surfaces such as cutting knives, wooden or steel tables, weighing scales, and other stainless steel equipment is an indicator of improper cleaning. 


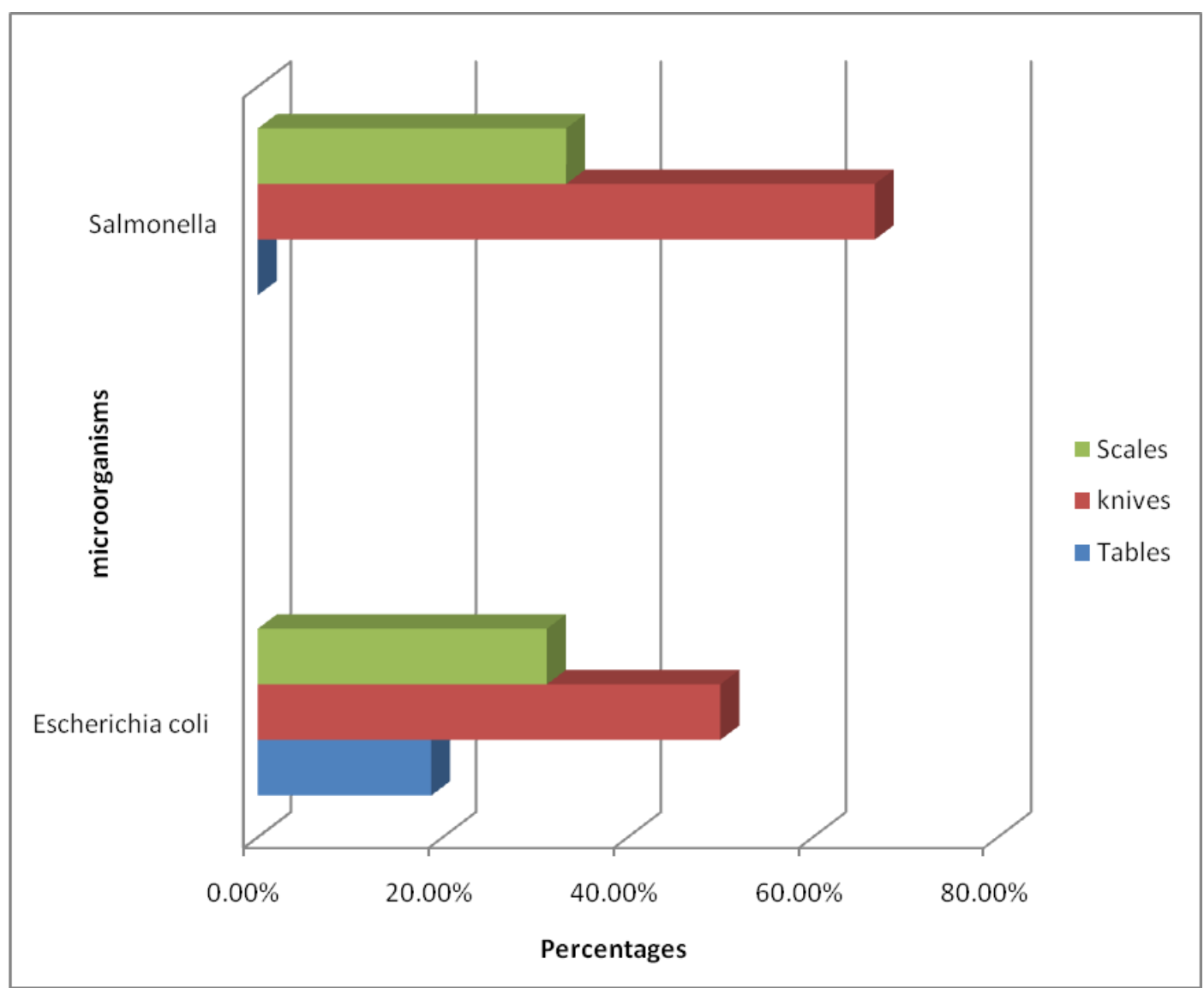

Figure 2. Salmonella and Escherichia coli isolated from poultry meat processing materials in percentages

The low rates of Escherichiacoli and Salmonella isolation from the wooden tables could be attributed to the fact that empty cartons of the poultry meat are placed on the tables instead of allowing direct contact between meat and table before cutting the meat into sizeable cuts. Salmonella cross-contamination in retail chicken outlets in Southern India was studied with Salmonella in Chopping boards at (18.75\%) and the butcher's hands (14.29\%) followed by knives and the weighing balance tray (Thiruppathiet al.,2004). The cartons are changed as often as the one being used is damaged which helped in reducing bacterial load on their surfaces however, prevalence of these organisms is a reflection of the fact that their microbial quality is poor. The rate of Escherichiacoli and Salmonella isolation observed with weighing scales could be attributed to the fact that several weighing scales are made available foruse so level of contamination is reduced however, the knives used are not been changed for the entire day hence the higher microbial level due to the accumulation of microorganisms and likely, biofilms on their surfaces. An indication of a possible source of recontamination in food handling and hygiene techniques (Clarenceet al., 2009) are the findings of this work.

\section{Recommendation}

1. Routine checks should be placed to monitor for the condition and cleanliness of meat sold in retail markets.

2. $40^{\circ} \mathrm{C}$ warm water for daily cleaning of surfaces such as stainless steel has been recommended by EC
(2001) to provide clean surfaces and to prevent coagulation of proteins on surfaces. Wooden tables should also be regulary washed and kept to dry before been used again. Therefore, multiple tables should be made available for sales of the meat and cartons placed on tables should be frequently changed.

3. Multiple knives and scales should be made available for use.

\section{Competing Interests}

The authors declare that they have no competing interests.

\section{References}

[1] American Public Health Association, 1992. Compendium of methods for the microbial examination of foods. 3rd rev. ed. C. Vanderzant and D.F. Splittstoesser, Washington, USA.

[2] Clarence S.Y, Obinna C.N, Shalom N. C. 2009.Assessment of bacteriological quality of ready to eat food (Meat pie) in Benin City metropolis, Nigeria. Afr. J. Microb. Res. 3(6), 390-395.

[3] Costerton J.W., Stewart P.S, Greenberg E.P., 1999. Bacterial Biofilms: A Common Cause of Persistent Infections Science 284: 1318-1322.

[4] Encyclopedia of Public Health 2011. E. Coli. http://www.enotes.com/public-health-encyclopedia/e-coli.

[5] European Commission (2001) In: The cleaning and disinfection of knives in the meat and poultry industry. http://ec.europa.eu/food/fs/sc/scv/out43_en.pdf.

[6] ERRB (Ethical Research Review Board) (2011) Research Management Office, University of Ibadan, Ibadan. http://rmo.ui.edu.ng/Structure\%20\&\%20Function.html. 
[7] Evans, J.A., Russel, S.L., James, C., Corry, J.E.L., 2004 Microbiological contamination of food refrigeration equipment. J. Food Eng. 62: 225-232.

[8] Global Salm-Surv (2003) In: Rene S (ed) A global Salmonella surveillance and laboratory support project of the World Health Organization. Laboratory Protocols Level 1 Training Course: Isolation of Salmonella, 4th edn., Hendriksen, pp 3-6,11,13,15,17.

[9] Gorman R, Bloomfield S, Adley C.C 2002. A study of crosscontamination of food-borne pathogens in the domestic kitchen in the Republic of Ireland.Int J Food Microbiol 76: 143-150.

[10] Hassan A.N, Amber F, Adnan K, Ameera Y. K. and Shahana U.K 2010.Microbial contamination ofraw meat and its environment in retail shops in Karachi, Pakistan. J Infect DevCtries2010; 4(6):382-388. Pg.384-386.

[11] ISO Standards catalogue 07.100.30 (2011) Food Microbiology. http://www.iso.org/iso/products/standards/catalogue_ics_browse.h tm? ICS1 $=07 \& I C S 2=100 \& I C S 3=30$.

[12] Magnus P. 1981.Meat Composition. Food Science and Technology, 4th edition. Gohumunary Pub., London, pp. 108-215.

[13] Mulder R.W. 1999. Hygiene during transport, slaughter and processing. In: Poultry Meat Science. Poultry Science Symposium Series (Richardson and Mead eds).Vol.25. pp. 277-285.

[14] National Institute of Allergy and Infectious Diseases, (NIAID) 2011. E. coli overview.

http://www.niaid.nih.gov/topics/ecoli/understanding/pages/overvie w.aspx.
[15] NSW Food Authourity (2011) In: NSW Retail Meat Food Safety Program, NSW/FA/FI024/1109. Pages 7, 14,16,20, 26,27,31,32. http://www.foodauthority.nsw.gov.au/_Documents/industry_pdf/h igh-risk-retail-meat-premises-food-safety-program.pdf.

[16] Panisello PJ, Rooney R, Quantick PC, Stanwell-Smith R.,2000.Application of foodborne disease outbreak data in the development and maintenance of HACCP systems.Int J Food Microbiol 59: 221-234

[17] SPSS/PC+, 1992. Base System User's Guide. Version 5.0. SPSS Inc.; Chicago, IL, USA.

[18] Thiruppathi S, Abdulla M. H., Dorairaj S., Sangeetha S. and Perumalsamy L.,2004.Salmonella Cross-contamination in Retail Chicken Outlets and the Efficacy of Spice Extracts on Salmonella enteritidis Growth Inhibition on Various Surfaces.Microbes and Environments, Vol.19, No. 4 pp.286-291.

[19] USDA, National Agricultural library (2011) Microbiological Standards and Guidelines., http://fsrio.nal.usda.gov/sanitation-and-qualitystandards/microbiological-standards-and-guidelines.

[20] WHO (2010) "Laboratory Protocol “. In: Isolation of Salmonella spp. From Food and Animal Faeces ” 5th Ed. June 2010. Pages 48,13 .

http://www.antimicrobialresistance.dk/data/images/protocols/isola tion_of_salm_220610.pdf. 